\title{
PATHOGENICITY FACTORS AND ANTIMICROBIAL RESISTANCE OF STAPHYLOCOCCUS EPIDERMIDIS ASSOCIATED WITH NOSOCOMIAL INFECTIONS OCCURRING IN INTENSIVE CARE UNITS
}

\author{
Lessandra Michelim ${ }^{1,2}$; Michele Lahude²; Patricia R. Araújoº ; Dirce S. H. Giovanaz² ; Gabriela Müller; \\ Ana P.L. Delamare ${ }^{1}$, Sérgio Olavo Pinto da Costa ${ }^{1}$; Sérgio Echeverrigaray ${ }^{1 *}$ \\ ${ }^{1}$ Laboratório de Biotecnologia Vegetal e Microbiologia Aplicada, Instituto de Biotecnologia, Universidade de Caxias do Sul, RS, \\ Brasil; ${ }^{2}$ Laboratório de Microbiologia, Hospital Geral de Caxias do Sul, RS, Brasil
}

Submitted: February 11, 2003; Returned to authors for corrections: July 03, 2004; Approved: March 28, 2005

\begin{abstract}
Nosocomial infections constitute an important problem in hospitals, intensive care units (ICU) having the highest incidence of this type of infection. Staphylococci, especially Staphylococcus epidermidis and Staphylococcus aureus, are among the most important microorganisms associated with nosocomial infections. S. epidermidis is a common skin resident, and can be introduced into the clinical environment by patients and hospital staff. The situation in hospitals is aggravated by the emergence of multiresistant strains. We evaluated 98 hospital S. epidermidis isolates collected at neonatal, pediatric and adult ICUs and 20 S. epidermidis control skin resident isolates from healthy volunteers, for resistance to ten antibiotics and chemotherapeutic agents, and other pathogenicity factors. A high frequency (76.5\%) of multiresistance was detected in clinical isolates, whereas community isolates were resistant to penicillin and ampicillin only. The frequency of multiresistant strains was $67.7 \%$ in the neonatal ICU, 66.6\% in the pediatric ICU and $60.8 \%$ in the adult ICU, the lower frequency of multiresistant isolates in the adult ICU indicates a higher incidence of community strains in this unit. There were significantly higher frequencies of hemolytic, proteolytic and biofilm-forming isolates in the clinical isolates than the community isolates, indicating a higher incidence of strains with pathogenic potential in the hospital environment. Except for slight correlation with hemolytic activity there was no correlation between antibiotic multiresistance and pathogenicity factors.
\end{abstract}

Key words: Staphylococcus epidermidis, pathogenicity factors, antibiotic resistance, hospital infection

\section{INTRODUCTION}

The occurrence of nosocomial infections acquired in hospitals or other clinical environments is considered an important problem both in Brazil and other parts of the world (1), intensive care units (ICUs) having the highest incidence of such infections because of the clinical condition of their patients (3).

The infectious agents most commonly isolated in ICUs are Staphylococcus epidermidis and Staphylococcus aureus (2), S. epidermidis being one of the principal skin residents present in practically all healthy and ill individuals, and can be introduced into the ICU by patients or medical staff and cause opportunistic infections during and after invasive procedures (7). Patients with lowered resistance can suffer endocarditis and septicemia associated with catheters, prosthetic implants and $S$. epidermidis, although it is often difficult to be certain that $S$. epidermidis is the causative agent as opposed to merely a normal part of the patients skin microflora or simply a contaminant $(16,18)$.

Pathogenicity of $S$. epidermidis has been linked to resistance to antimicrobial agents (2), production of invasins $(10,13,25)$ and biofilm formation $(21,25)$. Oxacillin resistance is high, and in

*Corresponding Author. Mailing address: Biotecnologia Vegetal e Microbiologia Aplicada, Instituto de Biotecnologia, Universidade de Caxias do Sul, Rua Francisco Getúlio Vargas, 1130. 95001-970, Caxias, RS, Brasil. Fax: (+5554) 218-2149. E-mail: selaguna@yahoo.com.br 
some studies has been reported in as much as $80 \%$ of clinical isolates $(1,7)$. The same is true for other antimicrobial agents such as ciprofloxacin, clindamycin, erythromycin, and sulphamethoxazole/trimethoprim combinations, with vancomycin often being the only antibiotic effective against all S. epidermidis isolates (1). Hemolytic activity has been detected in some $S$. epidermidis strains, $\alpha$-hemolysin having been associated with neurotoxic activity and $\gamma$-hemolysin with a severe inflammatory response $(6,25)$, while lipase activity has been linked with the capacity to invade dermal and epidermal tissues (11) and proteolytic activity has been shown to play a fundamental role in tissue damage and host inflammatory response (22,25). Adherence factors (adhesins), which facilitate the formation of biofilms, have also been related to the proliferation of $S$. epidermidis on the surface of catheters and prosthetic implants and to tissue invasion $(1,21,25)$.

Considering the importance of $S$. epidermidis as a causal agent of nosocomial infections, in the present work we evaluate hospital isolates of $S$. epidermidis, obtained at ICUs of the General Hospital of Caxias do Sul (HCS), Caxias do Sul, Rio Grande do Sul, Brazil, for the resistance to antimicrobial agents, and the expression of presumptive pathogenicity factors, in order to assess the relevance of these factors as indicators of the invasive capacity of S. epidermidis.

\section{MATERIALS AND METHODS}

\section{Isolation procedure}

The isolates were obtained between January 2002 and February 2003 from samples submitted to the microbiology laboratory of the General Hospital of Caxias do Sul (HCS), Caxias do Sul, Rio Grande do Sul, Brazil. We selected 98 S. epidermidis isolates obtained from blood, catheters and other materials associated with patients interned in neonatal, pediatric and adult ICUs at HCS. Swabs were also taken from the forearms of healthy volunteers, not associated with the ICUs, and the S. epidermidis isolates obtained used as controls representing non-nosocomial 'community' isolates.

The $S$. epidermidis isolates were selected from colonies which had been growing at $35^{\circ} \mathrm{C}$ for $24-48$ hours on tryptone soya agar (TSA) (Oxoid, Basingstoke, UK) supplemented with 5\% (v/v) sheep's blood, by making Gram-stained smears and selecting colonies which gave Gram-positive cocci arranged in irregular clusters resembling bunches of grapes, characteristic of staphylococci. The presumptive staphylococci were inoculated into tryptone-soya broth (TSB) (Oxoid, Basingstoke, UK) and tested for their capacity to coagulate fresh citrated plasma according to the method of Moura et al. (19). S. epidermidis identification was carried out by automated MicroScan ${ }^{\circledR}$ panels (Dade Behring International Inc., West Sacramento, CA).

Bacterial growth was measured on TSB medium by optical density (590nm) determination after $24 \mathrm{~h}$ at $35^{\circ} \mathrm{C}$.

\section{Antibiotic susceptibility testing}

Antibiotic susceptibility of the $S$. epidermidis isolates was evaluated by the disk agar-diffusion method according to a standard method (20), using Merck ${ }^{\circledR}$ Müeller-Hinton agar and Sensifar $^{\circledR}$ (Cefar Diagnóstica, São Paulo, BR) antibiotic disks (ampicillin, 10; cephalothin, 30; ciprofloxacin, 05; clindamycin, 02; erythromycin, 15; gentamycin, 10; oxacillin, 01 ; penicillin, 10; sulphamethoxazole/trimethoprim, 25; vancomycin, 30 (Penicillin in international units (IU), all others in $\mu \mathrm{g}$ per disk). These antibiotics are those recommended for antibiotic susceptibility testing of staphylococci by the United States National Committee For Clinical Laboratory Standards (20). Internal quality control was carried out using the antibiotic susceptibility test described above and S. aureus (ATCC 25923) as a standard. In this study isolates resistant to more than six antibiotics were considered multiresistant.

\section{Detection of hemolytic, lipolytic and proteolytic activity}

For the evaluation of enzymatic activities, the isolates were initially grown in TSA at $37^{\circ} \mathrm{C}$ for $24 \mathrm{~h}$. All the enzymatic experiments were repeated twice with three replications per experiment.

Hemolytic activity of the isolates was assessed after $48 \mathrm{~h}$ incubation at $37^{\circ} \mathrm{C}$ on TSA supplemented with $5 \%$ (v/v) sheep's blood, isolates being classified according to the diameter of the halos of hemolysis.

Lipolytic activity was assessed by streaking the isolates onto Tween 20 (T20) agar (containing $\left(\mathrm{gl}^{-1}\right)$ : Peptone, 10; $\mathrm{NaCl}$, 5; $\mathrm{CaCl}_{2}, 0.1$; agar, 20; Tween 20, $1 \mathrm{~mL}$ per litre added after autoclaving.) and incubating the plates at $37^{\circ} \mathrm{C}$ for $72 \mathrm{~h}$. Lipase activity was determined by measuring the halos of precipitated Tween around the streaks.

Proteolytic activity was measured by inoculating the isolates onto modified TSA medium (TSAM, containing $\left(\mathrm{gl}^{-1}\right)$ : TSA, 40; gelatin, 7.5; agar, 20) and incubating at $37^{\circ} \mathrm{C}$ for $18-20$ hours. After incubation the plates were flooded with a saturated solution of ammonium sulfate to precipitate the proteins in the medium, isolates being classified according to the size of the halo of protein hydrolysis.

\section{Biofilm formation}

The capacity of the isolates to form biofilms was evaluated by the method described by Heilmann et al. (14). Briefly: the isolates were grown at $37^{\circ}$ for 18 hours in $10 \mathrm{~mL}$ of TSB supplemented with $2.5 \mathrm{gl}^{-1}$ of glucose (TSB-glucose), diluted 1:200 in TSB-glucose, $200 \mu \mathrm{L}$ transferred to each well of a 96well polystyrene tissue culture test plate (TPP, Switzerland) and the plates incubated at $37^{\circ} \mathrm{C}$ for $24 \mathrm{~h}$ The wells were washed with sterilized phosphate buffered saline (PBS, containing $\left.\left(\mathrm{gl}^{-1}\right): \mathrm{NaCl}, 8 ; \mathrm{KCl}, 0.2 ; \mathrm{Na}_{2} \mathrm{HPO}_{4}, 0.15 ; \mathrm{KH}_{2} \mathrm{PO}_{4}\right)$, air-dried and treated with alcoholic fucsin $(1 \% \mathrm{w} / \mathrm{v})$ for 30 minutes to stain any adhered cells. Biofilm formation was evaluated visually, 
and quantified by absorbance at $490 \mathrm{~nm}$ using an enzyme-linked immunosorbent assay (ELISA) reader $\left(\right.$ Metrolab $^{\circledR}$, Buenos Aires, Argentina).

\section{Statistical analysis}

The results were analyzed statistically using various methods, including chi-square, Spearman correlation, frequency analysis and the Kruskal-Wallis test (nonparametric analog of one-way analysis of variance and detects differences in distribution location). All statistical analyses were conducted using version 10.1 of the SPSS program.

\section{RESULTS AND DISCUSSION}

\section{Resistance to antimicrobial agents}

Nosocomial infections caused by multiresistant staphylococci are a growing problem for many health service institutions $(15,23)$ because such infections restrict the number of antibiotics available for treatment. This situation is particularly serious in the case of $S$. epidermidis, an etiological agent of several nosocomial infections (bacteremia, endocarditis, osteomyelitis, peritonitis, postoperative cardiac infections, urinary-tract infections), and which is frequently associated with the colonization of catheters and implants (2). Within this context, the evaluation of resistance to antimicrobial agents in clinical and community isolates can contribute to understand the distribution and transmission of resistance, and help in the selection of appropriate antimicrobial therapy.

Our results showed that both the clinical and control isolates were resistant to penicillin and ampicillin. Resistance to these two antibiotics was the only resistance encountered in the 20 community isolates. Of the 98 clinical isolates, $82.6 \%$ were resistant to gentamycin, $79.6 \%$ to erythromycin, $76.5 \%$ to sulphamethoxazole/trimethoprim, $74.5 \%$ to clindamycin, $72.4 \%$ to cephalothin and oxacillin, and $71.4 \%$ to ciprofloxacin. All the isolates were susceptible to vancomycin.

Among clinical isolates, $72.4 \%$ were resistant to all the $\beta$-lactam antibiotics tested. In this sense, various studies have shown that staphylococci resistant to oxacillin are resistant to all penicillins (including semi-synthetic penicillins congruent resistant to $\beta$-lactamases) as well as penens, carbapenens and cephalosporins $(4,8,9)$. Staphylococcal resistance to these chemotherapeutic agents having been attributed to the production of the PBP-2' protein which links to the antibiotics (2). An elevated frequency of oxacillin resistance has been described by various authors for isolates obtained from nosocomial infections $(1,5,26)$.

All the community isolates and $27.6 \%$ of the clinical isolates were resistant to penicillin and ampicillin only. The resistance to these antibiotics has being attributed to the production of a restricted spectrum penicillinase or $\beta$-lactamase (2). Despite the low number of community isolates, the absence of multiresistant isolates among these samples suggest a selection for multiresistance within the hospital environment.

As in other studies $(1,2,17)$, a high frequency of hospital isolates with resistance to erythromycin, gentamicin and sulphamethoxazole/trimethoprim was observed. Moreover, clinical $S$. epidermidis isolates exhibited a high frequency of resistance to the two antibiotics considered among the most efficient for the control of staphylococci, clindamycin and ciprofloxacin, which meant that the only antibiotic tested which was effective against all the isolates was vancomycin. Von Eiff et al. (24) have shown that resistance to erythromycin and clindamycin is probably associated with the macrolidlincosamid-streptograminB phenotype, which may explain the strong correlation (95\%) we observed between resistances to these antibiotics.

Fig. 1 shows that the majority $(76.5 \%)$ of the S. epidermidis clones isolated from nosocomial infections were multiresistant, exhibiting resistance to more than six of the antibiotics tested. It should be pointed out once again that the community isolates were only resistant to ampicillin and penicillin, being sensitive to all the other antibiotics tested as well as to the sulphamethoxazole/ trimethoprim combination.

Clinical isolates of multiresistant staphylococci have been described by various authors (2,3). Von Eiff et al. (24) studying staphylococci isolated from blood-cultures found that resistance to ciprofloxacin, clindamycin, erythromycin, gentamycin, oxacillin and penicillin occurred in 40 to $96 \%$ of the isolates, many of which presented resistance most of the antibiotics tested, except for the glycopeptides vancomycin and teicoplanin.

The present results indicate that the staphylococcal isolates present in the ICUs examined were distinct from the non-clinical control isolates collected from the wider community, the absence of multiresistance in the community isolates pointing to the fact that the multiresistant clinical isolates were endemic to the hospital environment where they could cause contamination during hospitalization. There was also a significant (Kluskal-Wallis test) difference between the three ICUs in regard to multiresistant isolates that were only susceptible to vancomycin $(67.7 \%$ and

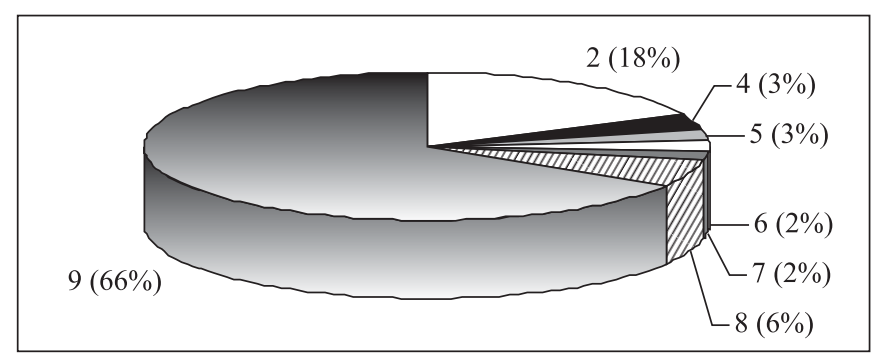

Figure 1. Percentage of hospital isolates resistant to between two and nine antibiotics. In this study isolates resistant to more than six antibiotics were considered multiresistant. 
$66.6 \%$ in the neonatal and the pediatric ICUs, compared with $60.8 \% \%$ in the adult ICU). This difference can be attributable to a higher incidence of community strains in the adult patients and shorter patient stays with a concomitant reduction in the possibility of infection by hospital strains of staphylococcus.

Significant difference was not observed between the frequency of multiresistant isolates from hemoculture (61\%), catheters $(68 \%)$, and other sources (66\%), indicating that antibiotic multiresistance pattern is a general feature of $S$. epidermidis from hospital units independent of the material source.

As there are no previous data on the relative occurrence of multiresistant strains in the different sectors of the ICUs in other hospitals, and considering that it dependents on a series of variables peculiar to each institution, including frequency of post-operative patients, most frequent type of pathology, socioeconomic status of the patients, efficiency of the infection control system, etc.; the differences between units should be considered of local validity.

\section{Pathogenicity factors}

Although various pathogenicity factors have been described in S. epidermidis the principal ones have been biofilms $(21,25)$, hemolysins $(13,25)$, lipases and proteases $(10,25)$. Based on this previous observations clinical and community isolates were evaluated for the presence of pathogenicity factors (Fig. 2 , Table 1) as an attempt to determine the pathogenic potential of $S$. epidermidis isolates.

Little is known about the importance of hemolytic activity as a pathogenicity factor in S. epidermidis, although $\alpha$ and $\gamma$ hemolysins have been detected in some $S$. epidermidis isolates (10). The overall frequency of hemolytic activity in our isolates was $35.5 \%$, agreeing with the low frequency for this trait in $S$. epidermidis reported by other workers (2). Although there was no clear picture regarding the role of hemolytic activity in pathogenicity (25), we found a significantly higher frequency of hemolytic activity in the clinical isolates (37.7\%) than in the community isolates $(20 \%)$. Moreover, the percentage of hemolytic isolates (Table 1) obtained from the pediatric UCI was significantly higher than that obtained for the other units. As it is difficult do explain, his difference may be confirmed by the analysis of a higher number of isolates. Supporting previous results $(2,25)$, the absence of significant differences between the percentage of hemolytic isolates from hemoculture and catheter can be taken as an indicative that this activity is not an essential pathogenicity factor of $S$. epidermidis.

Extracellular lipases have been shown to be a pathogenicity factor of various microorganisms, including S. epidermidis (10), contributing for the survival of microorganisms in environments containing high concentrations of lipids, and affecting the capacity of the microorganism to penetrate the skin and invade epidermal tissues. Among the isolates of S. epidermidis the
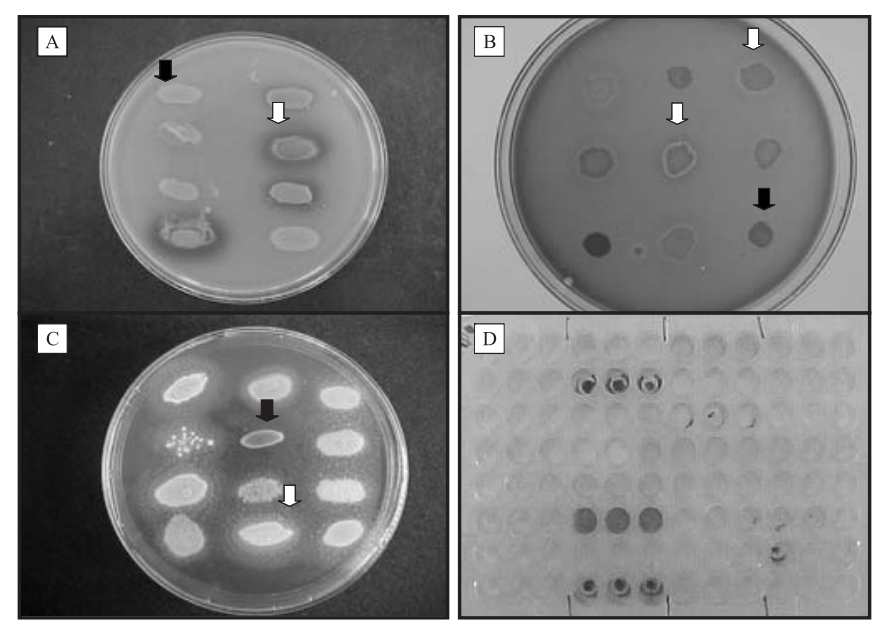

Figure 2. Occurrence of characteristics associated with pathogenicity among S. epidermidis hospital isolates: (A) proteolysis; (B) hemolysis; (C) lipolysis; (D) biofilm formation. No activity $\Omega$ Activity.

high majority (90\%) were positive for lipase activity. No differences on the percentage of lipolytic isolates were found when comparing clinical and community isolates, indicating that lipolytic activity is important not only during pathogenic processes but also for $S$. epidermidis skin colonization.

Proteases, like lipases, have been shown to be involved in tissue damage and the inflammatory response of the host (11), as well as in the degradation of signal peptides (e.g. human neutrophil proteins (HNPs), antimicrobial platelet proteins, antibodies) altering the immune response (22). Although the overall frequency of proteolytic isolates was $45.7 \%$ there was a significant difference between clinical isolates (49\%) and community isolates (30\%), indicating the importance of this factor in the S. epidermidis infectious process. However, no significant differences were obtained when comparing the percentage of proteolytic isolates from hemocultures and catheters, or those obtained from the different ICUs (Table 1).

Although diverse pathogenicity factors have been described in S. epidermidis, adhesion properties and biofilm formation has been considered as the most important pathogenicity factor of this species $(9,21,25)$. Biofilm formation was found to occur in $35.6 \%$ of our isolates, with a significant difference between the clinical isolates (38.8\%) and the community isolates (20\%). These results agree with previous work (9) suggesting that biofilm formation is an important pathogenicity factor, although the relatively low percentage of biofilm-forming isolates in our sample suggests that this is not an essential factor in $S$. epidermidis pathogenicity and that other factors are involved in the infective process of this organism. As for the other pathogenicity factors no significant differences on the 
percentage of biofilm forming isolates (Table 1) were observed when comparing different material sources or origins.

Quantitative evaluation of biofilms showed important variations of intensity, with $22.4 \%$ of our clinical isolates produced biofilms with an average to elevated intensity, while $16.3 \%$ exhibited weak or thin biofilms. Differences in biofilm intensity have been associated to variations of the expression of several genes related to the initial adhesion step and the later accumulation of secreted compounds $(16,21)$. Normal biofilms consist mainly of secreted material as opposed to cells, so if only the first step occurs or if there is sparse production of some components the result is a thin biofilm (12).

As can be seen from Table 2, few correlations were obtained for the factors investigated. Microbial growth showed a positive correlation with lipase activity but negative correlations with proteolytic activity and multiresistance, while although hemolytic activity was correlated with lipase activity and multiresistance it was negatively correlated with biofilm formation and proteolytic activity. There was no correlation at $\mathrm{p}=0.01$ between biofilm formation and the other pathogenicity factors evaluated nor, except for a weak negative correlation for hemolytic activity, was there any correlation between the pathogenicity factors and the origin of the isolates (catheters, blood, skin). The absence of correlation between the occurrence of pathogenicity factors can be seen as an indicative that none of the factors evaluated played a preponderant role in $S$. epidermidis pathogenesis, although all of them may contribute to some extent to the infectious process.

In summary, the data obtained in the present work conformed the importance of antibiotic resistance and the necessity of

Table 1. Percentage of $S$. epidermidis isolates expressing pathogenicity factors according with the material source and origin.

\begin{tabular}{lccccccc}
\hline \multirow{2}{*}{ Pathogenicity factors } & \multicolumn{3}{c}{ Material Source } & \multicolumn{4}{c}{ Material Origin } \\
\cline { 2 - 8 } & $\begin{array}{c}\text { Hemoculture } \\
\mathrm{n}=57\end{array}$ & $\begin{array}{c}\text { Catheter } \\
\mathrm{n}=35\end{array}$ & $\begin{array}{c}\text { Others }^{\mathrm{a}} \\
\mathrm{n}=6\end{array}$ & $\begin{array}{c}\text { Control } \\
\mathrm{n}=20\end{array}$ & $\begin{array}{c}\text { UTI-N } \\
\mathrm{n}=31\end{array}$ & $\begin{array}{c}\text { UTI-P } \\
\mathrm{n}=21\end{array}$ & $\begin{array}{c}\text { UTI-A } \\
\mathrm{n}=46\end{array}$ \\
\hline Hemolytic activity & 29.8 & 48.6 & 50.0 & $25.0^{*}$ & 40.9 & $75.0^{*}$ & 41.3 \\
Lipolytic activity & 87.7 & 97.1 & 83.3 & 95.0 & 87.1 & 90.5 & 93.5 \\
Proteolytic activity & 50.9 & 54.3 & 100.0 & 30.0 & $61.3^{*}$ & 47.6 & 41.3 \\
Biofilm formation & 45.6 & 45.7 & 33.3 & $20.0^{*}$ & 35.5 & 33.3 & 50.0 \\
\hline
\end{tabular}

a This data should be taken with caution as they are originated from a " $n$ " value of just 6 isolates.

* Significant different values (Chi-square analysis).

Table 2. Correlation between the expression of putative pathogenicity factors, multiresistance to antibiotics, sample origin, and material source of $S$. epidermidis isolates.

\begin{tabular}{llllllll}
\hline & Hemolysis & Lipolysis & Proteolysis & Biofilm & $\begin{array}{c}\text { Multi- } \\
\text { resistence }\end{array}$ & $\begin{array}{l}\text { Isolate } \\
\text { Origin }^{3}\end{array}$ & Material Source $^{4}$ \\
\cline { 2 - 7 } Bacterial growth & $0.085^{\text {n.s. }}$ & $0.249^{* *}$ & $-0.452^{* * *}$ & $-0.046^{\text {n.s. }}$ & $-0.203^{*}$ & $0.065^{\text {n.s. }}$ & $0.054^{\text {n.s. }}$ \\
& $0.179^{2}$ & 0.003 & 0.000 & 0.309 & 0.014 & 0.243 & 0.281 \\
Hemolysis & & $0.229^{* *}$ & $-0.126^{\text {n.s. }}$ & $0.097^{\text {n.s. }}$ & $-0.156^{*}$ & $0.116^{*}$ & $0.000^{\text {n.s. }}$ \\
& & 0.006 & 0.087 & 0.148 & 0.046 & 0.041 & 0.500 \\
Lipolysis & & $-0.076^{\text {n.s. }}$ & $-0.079^{\text {n.s. }}$ & $-0.034^{\text {n.s. }}$ & $0.029^{\text {n.s. }}$ & $0.102^{\text {n.s. }}$ \\
& & & 0.207 & 0.198 & 0.356 & 0.379 & 0.135 \\
Proteolysis & & & $0.017^{\text {n.s. }}$ & $0.129^{\text {n.s. }}$ & $0.149^{\text {n.s. }}$ & $0.165^{*}$ \\
Biofilm & & & 0.429 & 0.082 & 0.053 & 0.037 \\
& & & & $0.025^{\text {n.s. }}$ & $0.062^{\text {n.s. }}$ & $0.098^{\text {n.s. }}$ \\
\hline
\end{tabular}

${ }^{1}$ Spearman correlation, ${ }^{2}$ Significance $\left(1\right.$-tailed test). NS = not significant; ${ }^{*}=$ significant at $\mathrm{p}=0.05 ;{ }^{* *}=$ significant at $\mathrm{p}=0.01$;

${ }^{3}$ Isolate origin: catheters, blood, skin; ${ }^{4}$ Material source: community isolates, neonatal ICU, pediatric ICU, and adult ICU. 
particular care in the antibiotic treatment of nosocomial infections by $S$. epidermidis. The evaluation of pathogenicity factor, although there are significantly higher in clinical isolates, is not a good indicator of the invasive capacity of S. epidermidis. In general, the present results indicate that $S$. epidermidis populations that inhabitate the hospital environment are the principal responsibles for nosocomial infections by this species.

\section{ACKNOWLEDGEMENTS}

The authors wish to thanks the Hospital Geral de Caxias do Sul for the kind access to the samples, and the University of Caxias do Sul for the financial support of this study.

\section{RESUMO}

Fatores de patogenicidade e resistência a antimicrobianos em Staphylococcus epidermidis associados a infecções nosocomiais em unidades de terapia intensiva

As infecções nosocomiais constituem um importante problema em hospitais, sendo que as unidades de terapia intensiva (UTI) apresentam a maior incidência deste tipo de infecções. Os estafilococos, especialmente $S$. epidermidis e $S$. aureus, estão entre os microrganismos mais importantes associados às infecções nosocomiais. S. epidermidis é uma espécie colonizante da pele, sendo frequentemente inoculado durante procedimentos invasivos ou veiculado pela equipe de saúde, e essa situação é agravada pela emergência de cepas multirresistentes endêmicas no ambiente hospitalar. No presente trabalho foi avaliada a resistência a antibióticos e presença de distintos fatores de patogenicidade em 98 isolados clínicos de S. epidermidis obtidos de vários materiais em unidades de terapia intensiva e 20 colonizantes de pele de voluntários saudáveis. Os resultados obtidos mostraram elevada frequiência de isolados clínicos multirresistentes a antibióticos (76,5\%), enquanto esta não foi detectada em isolados de voluntários saudáveis. A frequência de isolados multiresistentes foi $67,7 \%$ na UTI neonatal, 66,6\% na UTI pediátrica, e 60,8\% na UTI adulto, a menor frequiência de isolados multirresistentes na UTI adulto é indicativo de maior incidência de cepas comunitárias nesse local. As diferenças significativas na frequiência de isolados com atividades hemolítica, proteolítica e formação de biofilme, encontradas entre isolados clínicos e controles, indica a maior incidência de cepas com potencial patogênico no ambiente hospitalar. Não foi observada correlação entre multirresistência e fatores de patogenicidade, exceto uma baixa correlação positiva com a atividade hemolítica.

Palavras-chave: Staphylococcus epidermidis, fatores de patogenicidade, resistência antimicrobiana, infecção hospitalar.

\section{REFERENCES}

1. Archer, G.L. Staphylococcus epidermidis and other coagulasenegative staphylococci. In: Mandell, G.L.; Bennett, J.E. and Dolin, R. (ed). Mandell, Douglas and Bennett's Principles and Practice of Infectious Diseases. $5^{\text {th }}$ ed. Churchill Livingstone, Philadelphia, 1999, p.2092-2100.

2. Boyce, J.M. Coagulase-negative Staphylococci. In: Mayhall, C.G. (ed). Hospital Epidemiology and Infection Control, $2^{\text {nd }}$ ed. Lippincott Williams \& Wilkins, Philadelphia, 1999, p.365-383.

3. Cavalcante, N.J.; Factore, L.A.; Fernandes, A.T.; Barros, E.R. Unidade de Terapia Intensiva. In: Fernandes, A.T.; Fernandes, M.O.; Ribeiro Filho, N. (ed.). Infecção Hospitalar e suas Interfaces na Área da Saúde. Atheneu, São Paulo, 2000, p.749-770.

4. Chambers, H.F. Oxacillin resistance in staphylococci: molecular and biochemical basis and clinical implications. Clin. Microbiol. Rev., 10, 781-791, 1997.

5. De Giusti, M.; Pacifico, L.; Tufi, D.; Panero, A.; Boccia, A.; Chiesa, C. Phenotypic detection of nosocomial mecA- positive coagulase negative staphylococci from neonates. J. Antimicrob. Chemother., 44, 351-358, 1999.

6. Dinges, M.M.; Orwin, P.M.; Schlievert, P.M. Exotoxins of Staphylococcus aureus. Clin. Microbiol. Rev., 13, 16-34, 2000.

7. Eggimann, P.; Pittet, D. Catheter-Related Infections in Intensive Care Units: an Overview with Special Emphasis on Prevention. Adv. Sepsis, 1, 2-15, 2000.

8. Fey, P.D.; Ulphani, J.S.; Gotz, F.; Heilmann, C.; Mack, D.; Rupp, M.E. Characterization of the relationship between polysaccharide intercellular adhesin and hemagglutination in Staphylococcus epidermidis. J. Infect. Dis., 179, 1561-1564, 1999.

9. Frebourg, N.B.; Lefebvre, S.; Baert, S.; Lemeland, J.F. PCR-based assay for discrimination between invasive and contaminating Staphylococcus epidermidis strains. J. Clin. Microbiol., 38, 877-880, 2000.

10. Gemmell, G.C. Virulence characteristics of Staphylococcus epidermidis. J. Med. Microbiol., 22, 287-289, 1996.

11. Goguen, J.D.; Hole, N.P.; Subrahmanyam, Y.V. Proteases and bacterial virulence: a view from the trenches. Infect. Agents Dis., 4, 47-54, 1995.

12. Hartford, O.M.; Wann, E.R.; Hook, M.; Foster, T.J. Identification of residues in the Staphylococcus aureus fibrinogen- binding MSCRAMM clumping factor A (ClfA) that are important for ligand binding. J. Biol. Chem., 276, 2466-2473, 2001.

13. Hebert, G.A.; Hancock, G.A. Synergistic hemolysis exhibited by species of staphylococci. J. Clin. Microbiol., 22, 409-415, 1985.

14. Heilmann, C.; Schweitzer, O.; Gerke, C.; Vanittanakom, N.; Mack, D.; Gotz, F. Molecular basis of intercellular adhesion in the biofilmforming Staphylococcus epidermidis. Mol. Microbiol., 20, 10831091, 1996.

15. Kawamura,Y.; Hou, X.G.; Sultana, F.; Hirose, F.; Miyake, M.; Shu, S.E.; Ezaki, T. Distribution of Staphylococcus species among human clinical specimens and emended description of Staphylococcus caprae. J. Clin. Microbiol., 36, 2038-2042, 1998.

16. Mack, D.; Rohde, H.; Dobinsky, S. Identification of three essential regulatory gene loci governing expression of Staphylococcus epidermidis polysaccharide intercellular adhesin and biofilm formation. Infect. Immun., 68, 3799-3807, 2000.

17. Martineau, F.; Picard, F.; Lansac, N.; Ménard, C.; Roy, P.; Quellette, M.; Bergeron, M.G. Correlation between the resistance genotype determined by multiplex PCR assays and the antibiotic susceptibility patterns of Staphylococcus aureus and Staphylococcus epidermidis. Antimicob. Agents Chemother., 44, 231-238, 2000.

18. Miragaia, M.; Couto , I.; Pereira, S.F.F.; Kristinsson, K.G.; Westh, H.; Jarlow, J.O.; Carriço, J.; Almeida, J.; Sanches, I.S.; Lencastre, H. Molecular characterization of oxacillin-resistent Staphylococcus epidermidis clones: evidence of geographic dissemination. J. Clin. Microbiol., 40, 430-438, 2002. 
19. Moura, R.A.A.; Purchio, A.; Rossi, A.R.; Strufaldi, B.; Nogueira, D.M.; Hoxter, G.; Coutinho, J.O.; Almeida, T.V. Técnicas de laboratório. Atheneu, São Paulo, 1982, p.399.

20. National Committee For Clinical Laboratory Standards. Methods for dilution antimicrobial susceptibility tests for bacteria that grows aerobically. NCCLS document Vol 22 No 1. National Committee For Clinical Laboratory Standards. Wayne, Pa., 2002, p.50 e 96.

21. Pei, L.; Flock, J.I. Lack of fbe, the gene for a fibrinogen-binding protein from Staphylococcus epidermidis, reduces its adherence to fibrinogen-coated surfaces. Microb. Pathog., 31, 185-193, 2001.

22. Rao, M.B.; Tanksale, A.M.; Ghatge, M.S.; Deshpande, V.V. Molecular and biotechnological aspects of microbial proteases. Microbiol. Mol. Biol. Rev., 62, 597-635, 1998.
23. Rupp, M.E.; Archer, G.L. Coagulase-negative staphylococci: pathogens associated with medical progress. Clin. Infect. Dis., 19, 231-245, 1994

24. Von Eiff, C.; Reinert, R.R.; Kresken, M.; Brauers, J.; Hafner, D. Nation wide German multicenter study on prevalence of antibiotic resistance in staphylococcal bloodstream isolates and comparative in vitro activities of quinupristin dalfopristin. J. Clin. Microbiol., 38, 2819-2823, 2000.

25. Vuong, C.; Otto, M. Staphylococcus epidermidis infections. Microb. Infect., 4, 481-489, 2002.

26. York, M.K.; Gibbs, L.; Chehad, F.; Brooks, G.F. Comparison of PCR detection of mecA with standard susceptibility testing methods to determine methicilin resistance in coagulase-negative staphylococci. J. Clin. Microbiol., 34, 249-253, 1996. 